Original Article

\title{
DIRECT SPECTROPHOTOMETRIC DETERMINATION OF ATENOLOL AND TIMOLOL ANTI- HYPERTENSIVE DRUGS
}

\author{
AKRAM M. El-DIDAMONY1, MOFTAH A. MOUSTAFA ${ }^{2}$ \\ ${ }^{1}$ Chemistry Department, Faculty of Science, Zagazig University, Zagazig, 44519, Egypt, ${ }^{2}$ Chemistry Department, Faculty of Science, Omar El- \\ Moktar University, Tobruk, Libya \\ Email: ak_eldidamony@yahoo.com \\ Received: 16 Nov 2016 Revised and Accepted: 09 Jan 2017
}

\section{ABSTRACT}

Objective: Direct and sensitive spectrophotometric method is described for the quantitative determination of some anti-hypertensive drugs such as atenolol (ATN) and timolol (TIM) in pure forms as well as in their dosage forms.

Methods: The proposed method is based on the redox reaction between the selected drugs and $\mathrm{KMnO}_{4}$ in alkaline medium. The method involves treating the aqueous solution of the selected drugs with $\mathrm{KMnO}_{4}$ in alkaline medium and measuring the bluish-green product at 610 nm. The different experimental parameters affecting the development and stability of the color were carefully studied and optimized.

Results: The fixed-time method is adopted for constructing the calibration curves, which were found to be linear over the concentration ranges of $2.0-14 \mu \mathrm{g} / \mathrm{ml}$ and $2.0-28 \mu \mathrm{g} / \mathrm{ml}$ for ATN and TIM, respectively. The determination of the studied drugs by initial rate, variable time and rate constant method was workable with the calibration equations obtained but the fixed time method has been found to be more applicable.

Conclusion: The applicability of the proposed method was demonstrated by the determination of the selected drugs in both pure and in commercial dosage forms and has met the validation requirements.

Keywords: Atenolol, Timolol, Dosage forms, Spectrophotometry, Potassium permanganate

(C) 2016 The Authors. Published by Innovare Academic Sciences Pvt Ltd. This is an open access article under the CC BY license (http://creativecommons.org/licenses/by/4. 0/] DOI: http://dx.doi.org/10.22159/ijpps.2017v9i3.16198

\section{INTRODUCTION}

$\beta$-Blockers (or $\beta$-adrenergic antagonists) are a group of drugs widely used in the treatment of cardiovascular diseases (CVD), namely, arterial hypertension, cardiac arrhythmias, and angina pectoris as well as other types of pathologies such as anxiety or glaucoma [1]. The therapeutic effects of beta blockers are normally explained by their capacity to block the betaadrenoceptors, hindering access of the endogenous agonist's noradrenaline and adrenaline. Atenolol, 4-(2-hydroxy-3isopropylaminopropoxy) phenylacetamide (fig. 1a), which in therapeutics is known as a $\beta$-blocker and is widely used in the management of hypertension, angina pectoris, cardiac arrhythmias and myocardial infarction [2].

The drug is official in the Indian pharmacopoeia [3] and in the British pharmacopoeia [4]. Several analytical methods have been reported for the determination of atenolol in human plasma, urine, or pharmaceutical preparations, such as high-performance liquid chromatography [5-9], gas chromatography [10], liquid chromatography $[11,12]$. Other techniques include voltammetric [13-15], electrophoresis [16, 17], chemiluminescence [18-20], spectrofluorimetric [21], ultraviolet and visible spectrophotometry [22-27].

Timolol maleate, (-)-(S)-1-tert-butylamino-3-(4-morpholino-1, 2, 5thiadiazol-3-yloxy)-2-propanol (fig. 1b), is used as an antihypertensive and an antiglaucoma agent. Literature survey revealed that few methods have been reported for the determination of TIM in pharmaceutical preparations such as spectrophotometric methods [28-30]. Here, also, derivative ultraviolet $[31,32]$, high-performance liquid chromatography [33, 34], liquid chromatography [35], chemiluminescence [36] and electrophoresis [37]. Timolol is officially recognised in the USP [38] and BP [39]. There are few spectrophotometric methods for the determination of atenolol and timolol. Some reported methods suffer from one or more disadvantages such as critical dependence on acid/pH condition, heating and/or extraction step, use of use of organic solvents, longer contact time, less stable coloured species and expensive chemicals as indicated in table 1 . For these reasons, develop a new simple, spectrophotometric method for the determination of ATN and TIM in their pharmaceutical dosage forms using eco-friendly chemicals and free from the use of organic solvents.<smiles>CC(C)NCC(O)COc1ccc(CC(N)=O)cc1</smiles>

a- Atenolol<smiles>CC(C)(C)NC[C@H](O)COc1nsnc1N1CCOCC1</smiles>

b- Timolol maleate

Fig. 1: Chemical structure of a-atenolol and b-timolol maleate 
Table 1: Comparison of Beer's law limits of reported methods with the proposed method

\begin{tabular}{|c|c|c|c|c|}
\hline \multirow[t]{2}{*}{ Method } & \multirow{2}{*}{$\begin{array}{l}\lambda_{\max } \\
\mathrm{nm}\end{array}$} & \multicolumn{2}{|c|}{ Linear range, $\mu \mathrm{g} / \mathrm{ml}$} & \multirow[t]{2}{*}{ Ref } \\
\hline & & ATN & TIM & \\
\hline Derivative spectroscopy & 225.5 & $1-15$ & & 22 \\
\hline Correction methods & 250 & $5-70$ & & \\
\hline $\begin{array}{l}\text { Bromate-bromide mixture } \\
\text { bromate-bromide mixture }\end{array}$ & 520 & $0.5-4.0$ & & 23 \\
\hline A & 540 & $1-20$ & & 24 \\
\hline B & 445 & $2-40$ & & \\
\hline $\mathrm{C}$ & 630 & $1-8.0$ & & \\
\hline Ion-pair & & & & 25 \\
\hline $\mathrm{BPB}$ & 415 & $1-8$ & $1-10$ & \\
\hline BTB & & $1-9$ & $1-10$ & \\
\hline bromate-bromide mixture & & & & \\
\hline $\mathrm{I}_{2}$ & 360 & $0.5-9$ & & 26 \\
\hline Starch-I ${ }_{2}$ & 570 & $0.3-6$ & & \\
\hline DDQ & 590 & $3-48$ & & \\
\hline 2,4-Dinitrphenol & 420 & $2-24$ & & 27 \\
\hline Picric acid & 420 & $1.5-18$ & & \\
\hline Vanadometric spectrophotometric & 504 & & $2-20$ & 28 \\
\hline Drug-metal & 369.4 & & $20-200$ & 29 \\
\hline Ion-pair & 552.2 & & $1.6-16$ & \\
\hline Absorbance subtraction & 272.8 & & $5-60$ & 30 \\
\hline Amplitude modulation & & & $5-60$ & \\
\hline First derivative UV & 313 & & $5-85$ & 31 \\
\hline Second derivative UV & & & $2-35$ & \\
\hline Kinetic spectrophotometric & 610 & $2-14$ & $2-28$ & Proposed method \\
\hline
\end{tabular}

\section{MATERIALS AND METHODS}

\section{Chemicals and instruments}

All chemicals and reagents used were of analytical grade. High purity double distilled water was used throughout. Pharmaceutical grade atenolol and timolol maleate were received from Egyptian Pharmaceutical Industries (EIPICO), 10 ${ }^{\text {th }}$ of Ramadan City, Egypt; which were reported to be $99.8 \%$ purity, as a gift and were used as received. A stock standard solutions containing $10 \mathrm{mg}$ of ATN and TIM were prepared by dissolving appropriate weight of pure drugs in distilled water and made up to the mark in a $100 \mathrm{ml}$ calibrated flask for obtaining working concentration $(100 \mu \mathrm{g} / \mathrm{ml})$ for ATN and TIM. NaOH (BDH, UK), $1.0 \mathrm{M}$ aqueous solution was prepared by dissolving $4.0 \mathrm{~g}$ of the chemical in $100 \mathrm{ml}$ of water. A stock solution of $5.0 \times 10^{-3} \mathrm{M}$ $\mathrm{KMnO}_{4}$ (Aldrich) was prepared by dissolving an accurate weight in $10 \mathrm{ml}$ of warm distilled water, then completed to the mark in a $100 \mathrm{ml}$ calibrated flask and standardized using sodium oxalate and kept in the dark bottle.

All the absorbance spectral measurements were made using spectroscan 80 D double-beam UV/Vis spectrophotometer (Biotech Engineering Ltd., UK), with wavelength range 190-1100 nm, spectral bandwidth $2 \mathrm{~nm}$, with $10 \mathrm{~mm}$ matched quartz cells. A water bath shaker (NSW 133, New Delhi, India) was used to control the heating temperature for color development.

\section{Analytical procedure}

Appropriate volumes of ATN or TIM stock solution $(100 \mu \mathrm{g} / \mathrm{ml})$ were transferred into a series of $10 \mathrm{ml}$ standard flasks. To each flask, $2.0 \mathrm{ml}$ of $1.0 \mathrm{M} \mathrm{NaOH}$ followed by $2.0 \mathrm{ml}$ of $5 \times 10^{-3} \mathrm{M} \mathrm{KMnO}_{4}$ were added. The volume was made up to the mark using distilled water, mixed well for $25 \mathrm{~min}$ at room temperature. Afterwards, the absorbance of the solutions was measured at $610 \mathrm{~nm}$ against a reagent blank which was treated similarly. The calibration graph was then constructed by plotting the final concentration of each drug against the absorbance values which were measured at a fixed time. Alternatively, the corresponding regression equation was derived.

\section{Procedure for the tablets}

At least ten tablets of blokium $100 \mathrm{mg} /$ tablet (Pharco, Egypt) were powdered and a quantity of the powder equivalent to $10 \mathrm{mg}$ ATN was extracted by shaking with $10 \mathrm{ml}$ distilled water. The extracts were filtered into a $100 \mathrm{ml}$ calibrated flask and then diluted to the mark. The assay for ATN content was completed as described under procedures for calibration curves.

\section{Procedure for eye drops}

The TIM pharmaceutical preparations were cusimolol eye drops, Sterile Ophthalmic solution, $5 \mathrm{mg} / \mathrm{ml}$ (Rameda, $10^{\text {th }}$ of Ramadan City, Egypt). An accurate measured volume equivalent to $10 \mathrm{mg}$ of drug was transferred into a $100 \mathrm{ml}$ calibrated flask; diluted to the mark with distilled water. The assay for TIM content was completed as described under procedures for calibration curves.

\section{Validation methods}

Validation parameters of atenolol (ATN) and timolol (TIM) in pure and pharmaceutical formulations assay which were tested were included linearity, Sandell's sensitivity, accuracy, precision, range, limit of detection (LOD) and the limit of quantitation (LOQ) [40].

\section{RESULTS AND DISCUSSION}

\section{Optimization of the reaction conditions}

Potassium permanganate as a strong oxidizing agent was utilised extensively for the determination of several drugs. The proposed method is concerned with the treatment of the investigated drugs with a known excess amount of $\mathrm{KMnO}_{4}$ in $\mathrm{NaOH}$ medium for certain time at room temperature. The reaction between studied drugs with $\mathrm{KMnO}_{4}$ in alkaline solution yields a bluish-green color as a result of the manganate (VI) species, peaking at $610 \mathrm{~nm}$ (fig. 2). The absorbance of the colored solution increase with time and hence, a kinetically-based spectrophotometric method was elaborated for their assay in pharmaceutical formulations. The extent of formation of the manganate (VI) species depends on the reactants, alkalinity of the medium, order of addition of reactants, diluting solvent and temperature. Therefore, various experimental parameters affecting the development and stability of the reaction product were optimized by changing each variable in turn while keeping all others constant.

\section{Effect of $\mathrm{KMnO}_{4}$ concentration}

To study the effect of $\mathrm{KMnO}_{4}$ concentration, aliquots of the studied drugs were transferred into a series of $10 \mathrm{ml}$ volumetric flasks as cited in (table 2), followed by varying volumes of $5 \times 10^{-3} \mathrm{M}$ of $\mathrm{KMnO}_{4}$ 
$(0.2-2.2 .5 \mathrm{ml})$ and $2.0 \mathrm{ml}$ of $1.0 \mathrm{M} \mathrm{NaOH}$ solutions. The absorbance at $610 \mathrm{~nm}$ was measured at a fixed time of $25 \mathrm{~min}$. The reaction increased substantially with increasing the concentration of $\mathrm{KMnO}_{4}$. Maximum absorbance was obtained when $2.0 \mathrm{ml}$ of $5 \times 10^{-3} \mathrm{MKMnO}_{4}$ solution was used. Further increase in the concentration had no effect of the reaction.

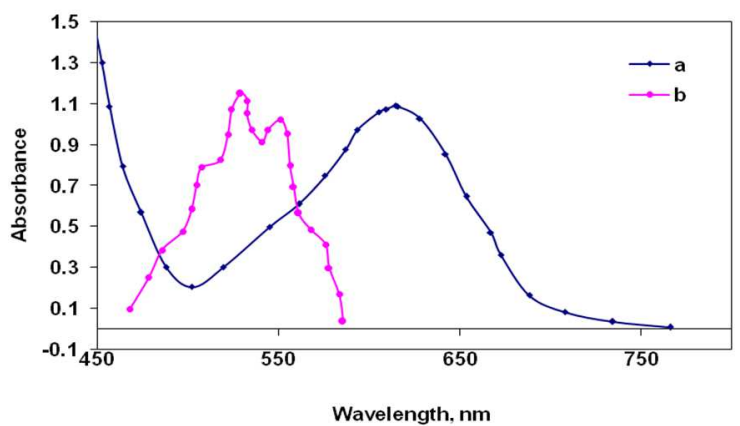

Fig. 2: Absorption spectra of the reaction product of (a) 14 $\mu \mathrm{g} / \mathrm{ml}$ atenolol after reaction with alkaline $\mathrm{KMnO}_{4}$ system against (b) reagent blank of $5 \times 10^{-3} \mathrm{M} \mathrm{KMnO}_{4}$

\section{Effect of $\mathrm{NaOH}$ concentration}

Effect of $\mathrm{NaOH}$ concentration on the reaction rate was studied using $0.2-3.0 \mathrm{ml}$ of $1.0 \mathrm{M} \mathrm{NaOH}$. It was found that increasing the volume of $1.0 \mathrm{M} \mathrm{NaOH}$, would increase the absorbance of the reaction product up to $2.0 \mathrm{ml}$. It was also observed that there was no significant difference in the absorbance of reactant solutions at $\mathrm{NaOH}$ concentrations above $1.5 \mathrm{ml}$, while decreasing $\mathrm{NaOH}$ concentration resulted in lower absorbance values. Therefore, $2.0 \mathrm{ml}$ of $1.0 \mathrm{M} \mathrm{NaOH}$ was found to be the most suitable concentration for maximum absorbance.

\section{Effect of temperature and time}

At room temperature the reaction rate increases substantially with time, although heating the solution was found to increase the rate of the reaction but $\mathrm{MnO}_{2}$ was precipitated. However, $25 \pm 2{ }^{\circ} \mathrm{C}$ was selected as the optimum temperature due to the low reproducibility of absorbance values obtained at higher temperatures. At room temperature, the reaction increased substantially with time, as revealed by the intensification of the developed color and subsequent increase in the slope of the calibration graph indicating high analytical sensitivity. The intensity of the color produced increased gradually and reached its maximum after $25 \mathrm{~min}$, where it remained stable for at least $1.0 \mathrm{~h}$.

\section{Order of addition}

The experimental parameters were fixed and further experiments were performed to test the influence of the order of the addition of reactants. It was found that the order drug, $\mathrm{KMnO}_{4}$ and $\mathrm{NaOH}$, results in maximum absorbance. Addition orders, other than that described in the procedure, gave lower results.

\section{Stoichiometric ratio}

The stoichiometric ratio between the studied drugs and potassium permanganate was determined by the limiting logarithmic method [41] by performing two sets of experiments. In the first set, the concentration of drugs was varied keeping a constant concentration of $\mathrm{KMnO}_{4}$. In the second set of experiment, the concentration of drugs was kept constant while varying the concentration of $\mathrm{KMnO}_{4}$. The logarithm of the absorbance was plotted against the logarithm of the respective varied concentration of drug or $\mathrm{KMnO}_{4}$. The slopes of the two straight lines were calculated and found to be unity in each case. Thus the stoichiometric ratio between each drug and potassium permanganate was found to be 1: 1 .

\section{Analytical parameters}

Under the experimental conditions described, standard calibration curves for ATN and TIM were constructed by plotting absorbance versus concentration (fig. 3). Conformity with Beer's law was evident in the concentration range of the final dilution cited in table 2. The calibration graphs are described by the equation:

$$
A=a+b X
$$

(Where $\mathrm{A}=$ absorbance, $\mathrm{a}=$ intercept, $\mathrm{b}=$ slope and $\mathrm{X}=$ concentration in $\mu \mathrm{g} / \mathrm{ml}$ ) obtained by the method of least squares. The correlation coefficient, intercept and slope for the calibration data are summarised in table 2. Sensitivity parameters such as apparent molar absorptivity and Sandell sensitivity values, the limits of detection and quantification are calculated and compiled in table 2 and are indicative of the excellent sensitivity of both methods. The limits of detection (LOD) and quantification (LOQ) were calculated according to the same guidelines using the formula:

$$
\text { LOD }=3.3 \% \text { and LOQ }=10 \%
$$

Where $\sigma$ is the standard deviation of five reagent blank determinations and $\mathrm{s}$ is the slope of the calibration curve.

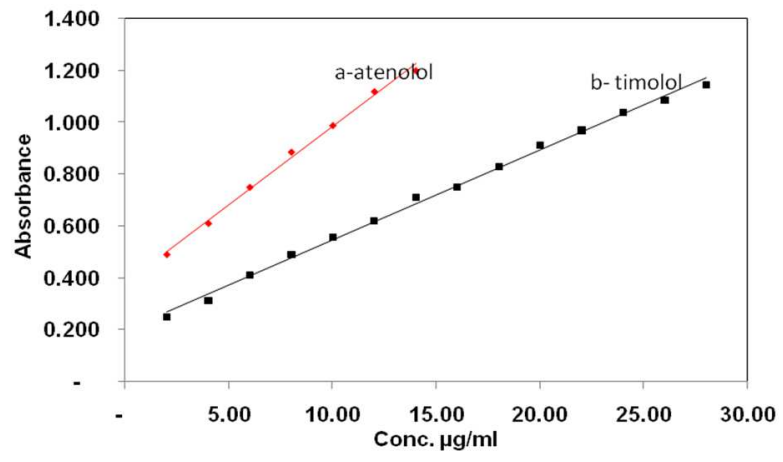

Fig. 3: Calibration curve of (a) atenolol $(2-14 \mu \mathrm{g} / \mathrm{ml})$ and (b) timolol $(2-28 \mu \mathrm{g} / \mathrm{ml}), 2.0 \mathrm{ml}$ of $1.0 \mathrm{M} \mathrm{NaOH}, 2.0 \mathrm{ml}$ of $5 \times 10^{-3} \mathrm{M}$ $\mathrm{KMnO}_{4}$ and mix for $25 \mathrm{~min}$

\begin{tabular}{|c|c|c|}
\hline Parameters & ATN & TIM \\
\hline$\lambda_{\max }(\mathrm{nm})$ & 610 & 610 \\
\hline Temp. ${ }^{\circ} \mathrm{C}$ & $25 \pm 2$ & $25 \pm 2$ \\
\hline Beer's law limit, $\mu \mathrm{g} / \mathrm{ml}$ & $2-14$ & $2-28$ \\
\hline Molar absorptivity, $1 \mathrm{~mol}^{-1} \mathrm{~cm}^{-1}$ & $2.03 \times 10^{4}$ & $1.74 \times 10^{4}$ \\
\hline Sandell's sensitivity, $\mathrm{ng} / \mathrm{cm}^{2}$ & 13.1 & 24.8 \\
\hline Correlation coefficient (r) & 0.9999 & 0.9998 \\
\hline \multicolumn{3}{|l|}{ Linear regression equation* } \\
\hline Intercept (a) & 0.340 & 0.201 \\
\hline Slope (b) & 0.057 & 0.038 \\
\hline$S_{y / x}$ & 0.046 & 0.026 \\
\hline SD of slope $\left(\mathrm{S}_{\mathrm{b}}\right)$ & 0.002 & 0.003 \\
\hline SD of intercept $\left(S_{a}\right)$ & 0.015 & 0.019 \\
\hline $\mathrm{LOD}, \mu \mathrm{g} / \mathrm{ml}$ & 0.081 & 0.181 \\
\hline $\mathrm{LOQ}, \mu \mathrm{g} / \mathrm{ml}$ & 0.351 & 0.789 \\
\hline
\end{tabular}

Table 2: Analytical parameters for the determination of atenolol and timolol in pure form

${ }^{*} \mathrm{~A}=\mathrm{a}+\mathrm{bC}$, where $\mathrm{A}$ is the absorbance and $\mathrm{C}$ is the concentration of drug in $\mu \mathrm{g} / \mathrm{ml}$, ATN: atenolol and TIM: timolol 


\section{Accuracy and precision}

The accuracy and precision of the proposed method were evaluated by performing five replicate analyses on pure drug solution at three different concentration levels (within the working ranges). The relative error (\%), an indicator of accuracy was within 0.3 and within day precision, also called the repeatability, expressed as relative standard deviation (RSD \%) was less than 2.7 indicating high accuracy and repeatability of the method. The results of the study are given in table 3.

Table 3: Evaluation of Intra-and inter-day precision and accuracy of the proposed method using alkaline $\mathrm{KMnO}_{4}$

\begin{tabular}{|c|c|c|c|c|c|c|}
\hline Frequency of analysis & Drugs & Drug taken $\mu \mathrm{g} / \mathrm{ml}$ & Recovery $^{a}, \%$ & RSD, \% & $\mathrm{RE}^{\mathrm{b}}, \%$ & $\mathrm{SE}^{\mathrm{c}}$ \\
\hline \multirow{3}{*}{ Intra } & ATN & 4.0 & 99.99 & 1.584 & -0.025 & 0.004 \\
\hline & & 8.0 & 99.96 & 1.349 & -0.088 & 0.017 \\
\hline & & 12 & 99.98 & 0.595 & -0.015 & 0.009 \\
\hline \multirow[t]{3}{*}{ Inter } & & 4.0 & 99.97 & 1.428 & -0.095 & 0.008 \\
\hline & & 8.0 & 99.96 & 2.424 & -0.178 & 0.005 \\
\hline & & 12 & 99.99 & 0.377 & -0.025 & 0.007 \\
\hline \multirow[t]{3}{*}{ Intra } & TIM & 4.0 & 99.95 & 2.418 & -0.201 & 0.038 \\
\hline & & 12 & 99.98 & 1.048 & -0.075 & 0.007 \\
\hline & & 20 & 99.99 & 0.125 & -0.007 & 0.005 \\
\hline \multirow[t]{3}{*}{ Inter } & & 4.0 & 99.96 & 2.661 & -0.265 & 0.039 \\
\hline & & 12 & 99.97 & 1.053 & -0.108 & 0.013 \\
\hline & & 20 & 99.99 & 0.173 & -0.015 & 0.007 \\
\hline
\end{tabular}

aMean value of five determinations, bRE: Relative error, cSE: standard error, ATN: atenolol and TIM: timolol

\section{Analysis of pharmaceutical formulations}

The fixed-time method has been successfully applied to determine ATN in tablets and TIM in eye drops.
The concentrations of the drugs were calculated using the corresponding regression equations at a fixed time of $25 \mathrm{~min}$ for both ATN and TIM. The results obtained are presented in table 4.

Table 4: Recovery of the studied drugs in formulations using the standard addition method using alkaline $\mathrm{KMnO}_{4}$

\begin{tabular}{|c|c|c|c|c|c|}
\hline Drugs & Drug taken $\mu \mathrm{g} / \mathrm{ml}$ & Drug found, $\mu \mathrm{g} / \mathrm{ml}$ & Recovery ${ }^{\mathrm{a}}, \%$ & RSD, \% & $\mathbf{R E}^{\mathbf{b}}, \%$ \\
\hline \multirow{3}{*}{ Blokiumc, $100 \mathrm{mg} /$ tablet } & 4.0 & 4.02 & 100.01 & 0.493 & 0.025 \\
\hline & 12 & 11.99 & 99.999 & 0.574 & -0.008 \\
\hline & 14 & 13.99 & 99.999 & 0.869 & -0.005 \\
\hline \multirow[t]{3}{*}{ Cusimolol eye drops ${ }^{\mathrm{d}}, 0.5 \%$} & 4.0 & 3.99 & 99.999 & 0.526 & -0.025 \\
\hline & 12 & 11.99 & 99.999 & 1.348 & -0.008 \\
\hline & 20 & 20.02 & 100.04 & 1.191 & -0.031 \\
\hline
\end{tabular}

aMean value of five determinations, bRE: Relative error, cMedical Union Pharmaceuticals, Ismailia, Egypt, dEgyptian Int Pharmaceutical Industries Co. (EIPICo) $10^{\text {th }}$ of Ramadan, Egypt

\section{Evaluation of the kinetic method}

The quantitative determination of ATN and TIM under the optimized experimental conditions outlined above would result in a pseudofirst order reaction with respect to their concentration where, $\mathrm{KMnO}_{4}$ concentration was at least 25 times of the concentration of each drug, and $\mathrm{NaOH}$ concentration was at least 300 times the initial concentration of each drug. However, the rates will be directly proportional to drugs concentration in a pseudo-first order rate equation as follows:

$$
\text { Rate }=\mathrm{K}+[\mathrm{C}]^{\mathrm{n}}(1)
$$

Equation (1) was the basis for several experiments, which were carried out to obtain drug concentration. The rate constant, fixedconcentration, and fixed time methods [42] were tried and the most suitable analytical method was selected taking into account the applicability, the sensitivity, the correlation coefficient $(r)$, and the intercept. Taking logarithms of rates and concentrations (table 5), the above equation becomes:

$$
\log \mathrm{K}=\log \Delta \mathrm{A} / \Delta \mathrm{t}=\log \mathrm{k}^{\prime}+\mathrm{n} \log \mathrm{C}
$$

Where $\mathrm{A}$ is the absorbance, $\mathrm{t}$ is the time in seconds and $\mathrm{K}$ is the pseudo-first order rate constant. Regression of log (K) versus log [C] gave the regression equations:

$\log K=\log \Delta A / \Delta t=-0.0077+0.6847 \log C, r=0.9964$ for ATN

$\log \mathrm{K}=\log \Delta \mathrm{A} / \Delta \mathrm{t}=1.2287+0.9502 \log \mathrm{C}, \mathrm{r}=0.9968$ for $\mathrm{TIM}$

A straight line with slope values of $(n \approx 1)$ was obtained confirming that the reaction was first order.

Table 5: Values of logarithms rates and concentrations of the studied drugs with alkaline $\mathrm{KMnO}_{4}$

\begin{tabular}{lllll}
\hline Drugs & $\log \boldsymbol{\Delta} \mathbf{A} / \mathbf{\Delta t}$ & Log [Drug] & Regression equation $\log \mathbf{\Delta} \mathbf{A} / \mathbf{\Delta} \mathbf{t}=\log \mathbf{k}^{\prime}+\mathbf{n} \log \mathbf{C}$ & Correlation coefficient (r) \\
\hline ATN & -3.316 & -4.823 & $\log \Delta \mathrm{A} / \Delta \mathrm{t}=-0.008+0.684 \log \mathrm{C}$ & 0.9964 \\
& -3.087 & -4.523 & & \\
& -2.987 & -4.346 & & \\
& -2.909 & -4.221 & & 0.9968 \\
TIM & -2.825 & -4.124 & $\log \Delta \mathrm{A} / \Delta \mathrm{t}=1.228+0.950 \log \mathrm{C}$ & \\
& -3.565 & -5.034 & & \\
& -3.258 & -4.733 & & \\
& -3.080 & -4.557 & & \\
& -2.989 & -4.432 & & \\
\hline
\end{tabular}

ATN: atenolol and TIM: timolol 


\section{Fixed-time method}

Reaction rates were determined for different concentrations of the investigated drugs. At a preselected fixed time, which was accurately determined, the absorbance was measured. Calibration graph of absorbance versus initial concentration of drugs was established at fixed time of 2, 5, 7, 11, 14, 17, 20, 25 and 30 min (fig. 4, 5) with the regression equation assembled in table 6 . It is clear that the slope increases with time and the most acceptable values of the correlation coefficient (r) and the intercept were obtained for a fixed time of $25 \mathrm{~min}$, which was therefore chosen as the most suitable time interval for measurement.

The analytical parameters for the determination of drugs in pure form by fixed time method are shown in table 6 . After optimising the reaction conditions, the fixed time method was applied to the determination of the studied drugs in pure form over the concentration range 2-14 and $2-28 \mu \mathrm{g} / \mathrm{ml}$ for ATN and TIM, respectively.

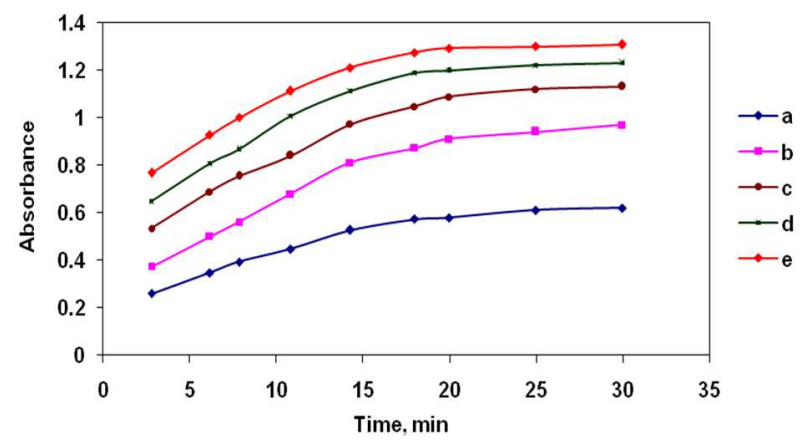

Fig. 4: Absorbance versus time graphs for the reaction of atenolol and alkaline potassium permanganate. Concentration of atenolol: (a) $1.50 \times 10^{-5}$, (b) $3.00 \times 10^{-5}$, (c) $4.51 \times 10^{-5}$, (d) $6.01 \times 10^{-5}$ and (e) $7.50 \times 10^{-5} \mathrm{M}$

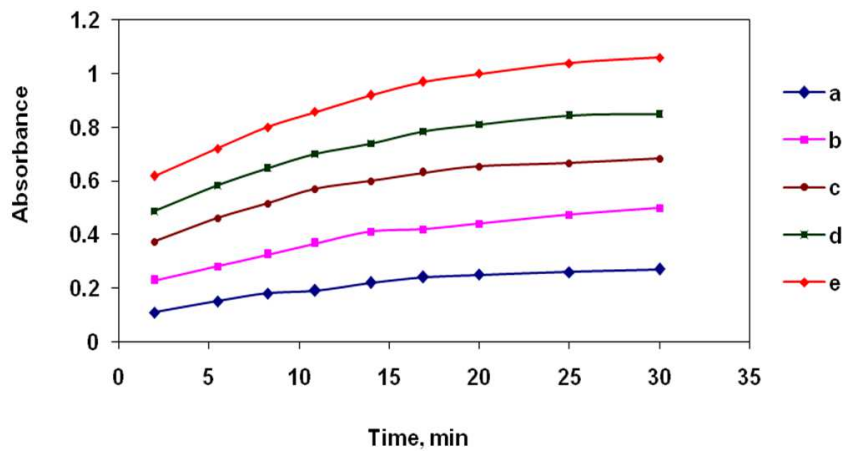

Fig. 5: Absorbance versus time graphs for the reaction of timolol and alkaline potassium permanganate. Concentration of timolol: (a) $9.25 \times 10^{-6}$, (b) $1.84 \times 10^{-5}$, (c) $2.77 \times 10^{-5}$, (d) $3.69 \times 10^{-5}$ and (e) $4.62 \times 10^{-5} \mathrm{M}$

Table 6: Regression equations for the studied drugs of different concentrations at different time intervals using fixed time method

\begin{tabular}{llll}
\hline Drugs & Time, $\mathbf{m i n}$ & Regression equation $* \mathbf{A}=\mathbf{a}+\mathbf{b C}$ & Correlation coefficient (r) \\
\hline ATN & 2 & $\mathrm{~A}=0.074+0.011 \mathrm{C}$ & 0.9912 \\
& 5 & $\mathrm{~A}=0.136+0.020 \mathrm{C}$ & 0.9867 \\
& 7 & $\mathrm{~A}=0.155+0.027 \mathrm{C}$ & 0.9868 \\
& 11 & $\mathrm{~A}=0.178+0.036 \mathrm{C}$ & 0.9776 \\
& 14 & $\mathrm{~A}=0.110+0.048 \mathrm{C}$ & 0.9966 \\
& 17 & $\mathrm{~A}=0.195+0.046 \mathrm{C}$ & 0.9888 \\
& 20 & $\mathrm{~A}=0.223+0.051 \mathrm{C}$ & 0.9892 \\
& 25 & $\mathrm{~A}=0.415+0.043 \mathrm{C}$ & 0.9999 \\
TIM & 2 & $\mathrm{~A}=-0.028+0.021 \mathrm{C}$ & 0.9986 \\
& 5 & $\mathrm{~A}=0.001+0.027 \mathrm{C}$ & 0.9879 \\
& 7 & $\mathrm{~A}=0.012+0.030 \mathrm{C}$ & 0.9991 \\
& 11 & $\mathrm{~A}=0.045+0.033 \mathrm{C}$ & 0.9894 \\
& 14 & $\mathrm{~A}=0.090+0.031 \mathrm{C}$ & 0.9859 \\
& 17 & $\mathrm{~A}=0.095+0.033 \mathrm{C}$ & 0.9889 \\
& 20 & $\mathrm{~A}=0.100+0.033 \mathrm{C}$ & 0.9853 \\
& 25 & $\mathrm{~A}=0.083+0.038 \mathrm{C}$ & 0.9998 \\
\hline
\end{tabular}

${ }^{*} \mathrm{~A}$ is the absorbance at $610 \mathrm{~nm}$ and $\mathrm{C}$ is the concentration in $\mu \mathrm{g} / \mathrm{ml}, \mathrm{ATN}$ : atenolol and TIM: timolol

\section{Rate constant method}

Graphs of log (absorbance) versus time for ATN concentrations in the range of $1.5 \times 10^{-5}$ to $7.51 \times 10^{-5} \mathrm{M}$ and TIM concentrations in the range of $9.23 \times 10^{-6}$ to $4.62 \times 10^{-5} \mathrm{M}$ were plotted and all appeared to be rectilinear. Pseudo-first-order rate constants (K) corresponding to different concentrations of the investigated drugs [C] were calculated from the slopes multiplied by-2.303 (table 7). Regression of $\mathrm{K}$ values versus [C] gave the equations:

$$
\begin{aligned}
& \mathrm{K}=-2.03 \times 10^{-4}+24.47 \log \mathrm{C}, \mathrm{r}=0.9999 \text { for } \mathrm{ATN} \\
& \mathrm{K}=-1.61 \times 10^{-4}+24.78 \mathrm{C}, \mathrm{r}=0.9998 \text { for TIM }
\end{aligned}
$$


Where $\mathrm{A}$ is the absorbance at $610 \mathrm{~nm}$ and $\mathrm{C}$ is the molar concentration. The method suffered from poor linearity as indicated from rvalue, therefore this method was excluded.

\section{Fixed absorbance method}

Reaction rates were determined for different concentrations of the investigated drugs. A pre-selected absorbance value was fixed at 0.5 for both ATN and TIM, for different concentrations of the studied drugs, in the range of $1.50 \times 10^{-5}$ to $7.51 \times 10^{-5} \mathrm{M}$ for ATE and $9.23 \times 10^{-6}$ to $4.62 \times 10^{-5} \mathrm{M}$ for TIM and the time required for each concentration to reach the preselected absorbance value was measured in seconds. The reciprocal of time $(1 / t)$ versus drug concentrations was plotted and the following equations were obtained by linear regression:

$$
1 / t=-0.00031+59.52 \mathrm{C}, \mathrm{r}=0.9988 \text { for ATN }
$$$$
1 / t=-0.00075+83.76 \mathrm{C}, \mathrm{r}=0.9707 \text { for TIM }
$$

The concentration ranges giving the most satisfactory calibration graphs were limited, therefore this method was abandoned.

Table 7: Values of $K$ calculated from slopes of $\log$ A versus $t$ graphs multiplied by-2.303 for different concentration of the studied drugs

\begin{tabular}{lllll}
\hline Drugs & [Drug] & K & Regression equation & Correlation coefficient (r) \\
\hline ATN & $1.50 \times 10^{-5}$ & $-1.61 \times 10^{-3}$ & $\mathrm{~K}=-2.037 \times 10^{-4}+24.47 \log \mathrm{C}$ & \\
& $3.00 \times 10^{-5}$ & $-1.38 \times 10^{-3}$ & & \\
& $4.51 \times 10^{-5}$ & $-1.15 \times 10^{-3}$ & & \\
& $6.01 \times 10^{-5}$ & $-9.21 \times 10^{-4}$ & & 0.9999 \\
TIM & $7.51 \times 10^{-5}$ & $-6.90 \times 10^{-4}$ & & \\
& $9.23 \times 10^{-6}$ & $-1.38 \times 10^{-3}$ & $\mathrm{~K}=-1.608 \times 10^{-4}+24.78 \log \mathrm{C}$ & \\
& $1.84 \times 10^{-5}$ & $-1.15 \times 10^{-3}$ & & \\
& $2.77 \times 10^{-5}$ & $-9.21 \times 10^{-4}$ & & \\
& $3.69 \times 10^{-5}$ & $-6.90 \times 10^{-4}$ & & \\
& $4.62 \times 10^{-5}$ & $-4.61 \times 10^{-4}$ & & \\
\hline
\end{tabular}

ATN: atenolol and TIM: timolol

\section{CONCLUSION}

The proposed spectrophotometric method is appreciable with a view that the oxidation of drugs can be exploited for the routine quality control analysis of ATN and TIM in pharmaceutical formulations. The method is sensitive with a simple calibration system that does not require any laborious cleanup procedure prior to analysis. Moreover, the present technique has the advantage of using inexpensive and easily available reagents and therefore can frequently be used in the laboratories of research, hospitals and pharmaceutical industries.

\section{CONFLICT OF INTERESTS}

Declared none

\section{REFERENCES}

1. Paterson JW. Citation classic-the pharmacodynamics and metabolism of propranolol in man. Current contents/clinical practice; 1982. p. 20.

2. Reynolds JEF. Ed. Martindale; Extra Pharmacopoeia. 28th ed. The Pharmaceutical Press: London; 1982. p. 1337.

3. The Indian Pharmacopoeia. 4th ed. The controller of publications, the ministry of health and family welfare, Government of India, New Delhi; 1996. p. 72.

4. The British Pharmacopoeia. Vol. I. Her Majesty's Stationery Office, London; 1988. p. 49.

5. El-Gindy A, Emara S, Mostafa A. HPLC and chemometricassisted spectrophotometric methods for simultaneous determination of atenolol, amiloride hydrochloride and chlorthalidone. IL Farmaco 2005;60:269-78.

6. Elgawish MS, Mostafa SM, Elshanawane AA. Simple and rapid HPLC method for simultaneous determination of atenolol and chlorthalidone in spiked human plasma. Saudi Pharm J 2011;19:43-9.

7. El-Gindy A, Sallam S, Abdel-Salam RA. HPLC method for the simultaneous determination of atenolol and chlorthalidone in human breast milk. J Sep Sci 2008;31:677-82.

8. Spanakis M, Niopas I. Determination of atenolol in human plasma by HPLC with fluorescence detection: validation and application in a pharmacokinetic study. J Chromatogr Sci 2013;51:128-32.

9. Neelima MS, Gandhi BM, Raju VB, Sumanth KS, Srinivas K, Mounika $\mathrm{P}$, et al. Development and validation of stability indicating a reverse phase high-performance liquid chromatography method for simultaneous estimation of atenolol, hydrochlorothiazide and losartan in bulk and pharmaceutical dosage form. Asian J Pharm Clin Res 2016;9:118-24.

10. Yilmaz B. Determination of atenolol in pharmaceutical preparations by gas chromatography with flame ionisation and mass spectrometric detection. Anal Lett 2010;43:2311-7.

11. Kannappan V, Mannemala SS. Simultaneous enantioseparation and purity determination of chiral switches of amlodipine and atenolol by liquid chromatography. J Pharm Biomed Anal 2016;120:221-7.

12. Lawson G, Cocks E, Tanna S. Quantitative determination of atenolol in dried blood spot samples by LC-HRMS: a potential method for assessing medication adherence. J Chromatogr B 2012;897:72-9.

13. Sartori ER, Medeiros RA, Rocha-Filho RC, Fatibello-Filho 0. Square-wave voltammetric determination of propranolol and atenolol in pharmaceuticals using a boron-doped diamond electrode. Talanta 2010;81:1418-24.

14. Goyal RN, Singh SP. Voltammetric determination of atenolol at C60-modified glassy carbon electrodes. Talanta 2006; 69:932-7.

15. Goyal RN, Gupta VK, Oyama M, Bachheti N. Differential pulse voltammetric determination of atenolol in pharmaceutical formulations and urine using nanogold modified indium tin oxide electrode. Electrochem Commun 2006;8:65-70.

16. Zzam KA, Elbashir AA, Elbashir MA, Saad B, Hamid SA. Simultaneous determination of atenolol and chlorthalidone in pharmaceutical preparations by capillary-zone electrophoresis. Anal Lett 2009;42:1458-70.

17. $\mathrm{Xu}$ L, Guo Q, Yu H, Huang J, You T. Simultaneous determination of three $\beta$-blockers at a carbon nanofiber paste electrode by capillary electrophoresis coupled with amperometric detection. Talanta 2012;97:462-7.

18. Wang $\mathrm{Y}, \mathrm{Wu} \mathrm{Q}$, Cheng $\mathrm{M}$, Cai C. Determination of $\beta$-blockers in pharmaceutical and human urine by capillary electrophoresis with electrochemiluminescence detection and studies on the pharmacokinetics. J Chromatogr B 2011;879:871-7.

19. Li D, Du J, Lu J. Chemiluminescence determination of atenolol in biological fluids by a europium-sensitized permanganatesulfite system. Microchim Acta 2008;161:169-73.

20. Al-arfaj NA, Al-Abdulkareem EA, Aly FA. Determination of enalapril maleate and atenolol in their pharmaceutical products and in biological fluids by flow-injection chemiluminescence. Luminescence 2009;24:422-8. 
21. Basan H, Yarımkaya S. A novel solid-phase extractionspectrofluorimetric method for the direct determination of atenolol in human urine. Luminescence 2014;29:225-9.

22. Thomas A, Patankar M, Deshmukh KR, Kothapalli L, Jangam S, Patankar PR, et al. Simultaneous spectrophotometric estimation of losartan potassium and atenolol in bulk and two component formulation. Asian J Chem 2007;19:3721-6.

23. Basavaiah K, Chandrashekar U, Nagegowda P. Titrimetric, spectrophotometric and kinetic methods for the assay of atenolol using bromate-bromide and methyl orange. J Serb Chem Soc 2006;71:553-63.

24. Prashanth KN, Basavaiah K. Sensitive spectrophotometric determination of atenolol in pharmaceutical formulations using the bromate-bromide mixture as an Eco-friendly brominating agent. J Anal Methods Chem 2012;2012:1-12.

25. Al-Ghannam SM. A simple spectrophotometric method for the determination of $\beta$-blockers in dosage forms. J Pharm Biomed Anal 2006; 40:151-6.

26. Prashanth kN, Basavaiah K, Abdulrahman SAM, Rajendraprasad N, Vinay BK. Application of bromated-bromide mixture as a green brominating agent for the spectrophotometric determination of arenolol in pharmaceuticals. Chem Ind Chem Eng Q 2012;18:43-52.

27. Prashanth KN, Basavaiah K. Simple, sensitive and selective spectrophotometric methods for the determination of atenolol in pharmaceuticals through charge transfer complex formation reaction. Acta Poloniae Pharm 2012;69:213-23.

28. Nnadi CO, Obonga WO, Ogbonna JDN, Ugwu LO. Development of vanadometric system for spectrophotometric determination of timolol in pure and dosage forms. Trop J Pharm Res 2015;14:2223-9.

29. Ayad MM, Shalaby A, Abdellatef HE, Hosny MM Spectrophotometric methods for determination of enalapril and timolol in bulk and in drug formulations. Anal Bioanal Chem 2003;375:556-60.

30. Lotfy HM, Hegazy MA, Rezk MR, Omran YR. Novel spectrophotometric methods for simultaneous determination of timolol and dorzolamide in their binary mixture. Spectrochim Acta A 2014;126:197-207.

31. Rizk MS, Merey HA, Tawakkol SM, Sweilam MN. Simultaneous determination of timolol maleate and brimonidine tartrate in their pharmaceutical dosage form. Anal Chem Lett 2014;4:132-45.
32. Hassib ST, Elkady EF, Sayed RM. Simultaneous determination of timolol maleate in combination with some other antiglaucoma drugs in rabbit aqueous humor by high-performance liquid chromatography-tandem mass spectroscopy. J Chromatogr B 2016;1022:109-17.

33. Hamdan II, Qurani H. Development and validation of a HPLC method for determination of potential residual cortisone compounds in timolol maleate eye drops. J Liq Chromatogr Relat Technol 2008;32:449-67.

34. Boiero C, Allemandi D, Longhi M, Llabot JM. RP-HPLC method development for the simultaneous determination of timolol maleate and human serum albumin in albumin nanoparticles. J Pharm Biomed Anal 2015;111:186-9.

35. Rizk MS, Merey HA, Tawakkol SM, Sweilam MN. Development and validation of a stability-indicating micellar liquid chromatographic method for the determination of timolol maleate in the presence of its degradation products. J Chromatogr Sci 2015;53:503-10.

36. Du J, Quan J, Wang Y. Chemiluminescence determination of timolol maleate by gold nanoparticles-catalyzed luminol-Nbromosuccinimide system. Talanta 2012;90:117-22.

37. Maguregui MI, Jimènez RM, Alonso RM, Akesolo U. Quantitative determination of oxprenolol and timolol in urine by capillary zone electrophoresis. J Chromatogr 2002;949:91-7.

38. United States Pharmacopoeia. 24th Rev. National Formulary, United States Pharmacopeial Convention. 2000. p. 638.

39. British Pharmacopoeia. HM Stationery Office, London; 1993. p. $641,692$.

40. Miller JC, Miller JN. "Significance tests in statistics for analytical chemistry", 3rd ed. Chap. 3. Hardwood, Chichester; 1993.

41. Rose J. Advanced Physicochemical Experiments, Pitman, London; 1964. p. 67.

42. Weisberger A, Friess SL, Lewis ES. In: Techniques of Organic Chemistry, Part I. Vol. III. Interscience, New York; 1953.

\section{How to cite this article}

- Akram M El-Didamony, Moftah A Moustafa. Direct spectrophotometric determination of atenolol and timolol antihypertensive drugs. Int J Pharm Pharm Sci 2017;9(3):47-53. 